\title{
THE APPLE TREATMENT OF INFANTILE DIARRHOEA
}

\author{
BY \\ WILFRID SHELDON, M.D., F.R.C.P., \\ Physician for Diseases of Children, King's College Hospital ; \\ Physician to Out-patients, Hospital for Sick Children, Great Ormond Street, \\ AND \\ MARCIA HALL, B.A., M.B., B.CH., \\ Research Associate, Hospital for Sick Children, Great Ormond Street.
}

Although the beneficial effect of apple in the treatment of diarrhoea seems to have been known for many years, it is only in the last decade that it has found a place in medical literature. Schachter (1934) in one of his communications on this subject refers to a description of apple therapy in dysentery in an English book published in 1775. Apparently the treatment has been an 'old wives' tale' in parts of Germany for many years, and during the last war it was found in a certain concentration camp that patients with dysentery who managed to secure apples growing in the grounds of the camp were quickly relieved of their symptoms.

The recent interest in the diet dates from Heisler's publication in 1929 entitled 'Apple, Sauerkraut, and Buttermilk Treatment of Infantile Diarrhoea.' In the same year Moro published an article entitled 'Apples in diet for the treatment of diarrhoeal conditions in children,' and since then several articles have referred to the treatment as the Moro-Heisler diet. Interest in this subject was at first centred in Germany, but it has now received practically a world-wide trial, and with few exceptions reports have been favourable. The literature up to the end of 1933 has been summarized by Schachter, and a report issued by the American Council on Foods refers to the more important publications up to 1937.

Although the apple diet has produced quite a big literature in Germany and the U.S.A., with contributions also from almost every European country, the Dominions, and Uruguay, little has appeared in the medical literature of this country. Schlesinger spoke of the treatment at the British Paediatric Association in 1936, and a brief précis of his remarks appeared in this journal later in the same year (Schlesinger, 1936). The only other article in this country is from the pen of Barondes, of San Francisco (1937). 
A review of the literature indicates that the treatment has been used in practically every type of diarrhoea met with in children. Cases of frank dysentery, of non-specific ulcerative colitis with blood and mucus in the stools, and of parenteral diarrhoea have apparently all been benefited; even so the treatment is not claimed as a specific cure, but rather as an adjunct to other more customary procedures, sometimes succeeding where other methods have failed. The treatment has also been used in children of all ages down to as young as two or three months.

The mode of preparation differs in different hands. Heisler originally stated that sour apples should be used, Moro advocated ripe sweet apples. Whether or not the peel should be removed is also a matter of opinion, and it has been stated that the apples should be cut up and allowed to stand until turned brown by the air. We are not in a position to pronounce on all these points, for we have not varied our method, a description of which appears later. Nor have we employed a dried apple pulp, traded under the name Aplona, for which success is claimed.

Apple pulp does not of itself contain sufficient water to satisfy a child's fluid requirements, and therefore extra fluid has to be given with the apple. Plain water may be used, others have advised a weak, freshly prepared infusion of tea, and this has been used in the present series of cases. The benefit of the tea is chiefly as a source of fluid ; the small amount of alkaloid in it may perhaps have some stimulating effect, but as the tea is freshly prepared the amount of tannin present is too small to exert a constipating action.

\section{Present investigation}

This communication gives the results of treatment in thirty-six babies, of whom thirty-four were treated at St. Giles' Hospital (London County Council), the treatment having been carried out under the supervision of one of us (W. S.).

Cases. The accompanying table gives details of the cases. Twenty-two were males, fourteen females. The age of the infants ranged from nine weeks to two years, the majority being between six and fifteen months. A point which perhaps should be emphasized is that the infants were drawn from a poor class and most of them were anaemic, puny and undernourished by the time of their admission to hospital. It is commonly taught that the initial treatment of infantile diarrhoea should consist of a purge, usually castor oil, provided that the child is not too feeble; with this in mind, the condition of the infants in this investigation can best be indicated by stating that practically none were judged strong enough to withstand a dose of castor oil.

In most of the infants diarrhoea had been present for at least a week, and although some of them were passing a dozen or more stools a day, more commonly the stools numbered four or five a day and were green, curdled and offensive in character. The cause of the diarrhoea varied. Four infants were regarded as suffering from acute infective diarrhoea, and although they all recovered the impression was obtained that recovery might equally have come 
about without recourse to apple. In thirteen the diarrhoea was associated with infective conditions elsewhere in the body, and so was regarded as parenteral ; in this group three infants died, two with an associated bronchopneumonia and the third with eczema and pyelitis. In twelve the diarrhoea was regarded as dietetic, the onset coinciding with weaning from the breast to some patent food or to a more solid diet, or changing from one patent food to another. Only two infants were entirely breast fed ; one developed diarrhoea secondary to bronchitis, the other, the youngest in the series, was a premature and wasted infant. Both improved rapidly after the apple diet, and resumed breast feeding.

Effect of treatment. Apart from the question of recovery, incidental effects were noted during treatment. At the end of twenty-four hours the tongue and buccal mucosa developed a peculiar brown discoloration, appearing as though slightly tanned, and the efforts of the nursing staff to remove this were quite unavailing; it persisted for at least a week after the apple was discontinued. Although coloured in this way the mouth did not appear to be parched, and sucking was not affected. As to vomiting, those infants who tolerated the diet ceased vomiting almost immediately ; in fact, it was only when an attempt was made to include the peel that vomiting seemed to be aggravated. The effect on the stools was noticeable ; by the end of the first full day's treatment the offensive odour disappeared, and the motions began to be formed and bulky. Their number was also reduced, and by the third day only one or two motions were passed ; in fact, in several infants the diarrhoea was by this time replaced by a mild constipation, no motions being passed for twenty-four hours. Together with this change in the stools, the appearance of toxaemia borne by many of the infants faded out. Their eyes brightened, they became more alert, and by the third day they had regained a good appetite. Another striking feature was the rapid gain in weight made by the majority of infants, often from the first day of treatment.

\section{Dietary technique}

Preliminary Treatment.-Although many of the cases began their apple treatment within a day or two of admission to hospital, others received a more customary type of treatment for several days, including measures to combat dehydration and a simple fluid diet, and it was only when these had not proved successful that resort was made to apple therapy. Invariably when dehydration was severe, efforts were made to overcome this by subcutaneous or intravenous salines before apple treatment was started.

PReParation of APPLE.-Various sorts of apple were tried, and it was soon realized that a brand with a soft flesh and plenty of juice facilitated preparation. Jonathan apples easily ranked first, followed by Sturmer Pippins and Cox's Orange Pippins. Newton Wonders were not suitable. The apples were peeled and then grated on a fine grater, the pulp and juice being fed as a mash. Each feed was prepared separately so that the pulp had not time to turn brown. At first an attempt was made to include the peel, but even when it was finely cut it seemed to make the infants vomit, and so was discontinued. 


\begin{tabular}{c|c|l|l}
\hline CASE No. & $\begin{array}{c}\text { AGE IN } \\
\text { MONTHS }\end{array}$ & \multicolumn{1}{|c|}{ DURATION OF DIARRHOEA } & \multicolumn{1}{|c}{ TYPE OF } \\
DiARROEA
\end{tabular}


THE APPLE TREATMENT OF INFANTILE DIARRHOEA

\begin{tabular}{|c|c|}
\hline COMPLications & Results and Remarks \\
\hline $\begin{array}{l}\text { Prematurity and marasmus } \\
\qquad-\end{array}$ & $\begin{array}{l}\text { Recovered. Breast-fed. } \\
\text { Recovered. Treated with apple-juice, but no pulp. The } \\
\text { juice was continued for } 4 \text { days. }\end{array}$ \\
\hline Twin & $\begin{array}{l}\text { Died. At first the infant did well and in the week after } \\
\text { apple gained } 8 \mathrm{oz} \text {. in weight. Then suddenly collapsed. } \\
\text { No post-mortem examination. }\end{array}$ \\
\hline Bronchitis & Recovered. \\
\hline 一 & Recovered. \\
\hline - & Recovered. \\
\hline - & Recovered. \\
\hline Pyelitis and bronchitis & Recovered. \\
\hline - & Recovered. Also had blood transfusion. \\
\hline Fractured femur in plaster & Recovered. \\
\hline Scurvy & Recovered. \\
\hline Bronchitis & Recovered. Breast-fed. \\
\hline Bronchopneumonia & Died. \\
\hline- & Recovered. \\
\hline Bronchopneumonia & Died. \\
\hline - & Recovered. \\
\hline Eczema and pyelitis & Died. \\
\hline- & Recovered. \\
\hline Otorrhoea ; bronchitis & Recovered. \\
\hline - & Recovered. \\
\hline 一 & Recovered. \\
\hline - & Recovered. \\
\hline 一 & Recovered. \\
\hline - & Recovered. \\
\hline - & Recovered. \\
\hline Otorrhoea & Recovered. \\
\hline Pyelitis & Recovered. \\
\hline Convulsions & Recovered. \\
\hline - & Recovered. \\
\hline Boils & Recovered. \\
\hline - & Recovered. \\
\hline Bronchitis & Recovered. \\
\hline - & Recovered. \\
\hline - & Recovered. \\
\hline Bronchitis & Recovered. \\
\hline- & Recovered. \\
\hline
\end{tabular}


Feeds were given either by spoon or from a bottle with a large-holed teat, according to the age of the infant, and were spaced at three-hourly intervals throughout day and night. The youngest infants received a teaspoonful at each feed, while at a year the pulp of a whole apple was given, equivalent to eight apples in twenty-four hours. When fed from a spoon the apple was abruptly discontinued after seventy-two hours, but when given from a bottle the pulp had to be diluted with water, and it was then found necessary to continue apple feeding for four days. During the following three days the diet was built up to a full and normal one according to the patient's age.

Preparation of TEA.- In order to bring the fluid intake up to the required level the patients treated earlier in the series were given water with the apple, but later on tea was given instead, and the majority of the patients received tea. Indian tea was used, and was prepared by infusing half a drachm of tea in half a pint of water. The tea was allowed to draw for two minutes only, and was given without milk or sugar. The amount was calculated on the basis of allowing two-and-a-half ounces per pound of body weight per day, the total amount for the day being divided into eight feeds at three-hourly intervals. One hour was allowed between an apple feed and the corresponding drink of tea.

The tea was not discontinued when the apple was stopped, but was fortified by additions of milk and sugar, until after two or three days the tea was omitted and a normal diet resumed.

\section{Mode of action}

The rationale underlying the treatment is not as yet completely understood. The most popular theory is that improvement is to be attributed to pectin, acting in virtue of a colloidal and buffering effect which prevents the absorption of intestinal toxins; these are then excreted in the stools. This seems not to be the whole story, however, for possibly the tannic acid compounds present in apple may have some astringent effect, and in this connexion attention has already been drawn to the browning which affects the mucous membrane of the mouth and tongue. Others have attributed the benefit to malic and other acids present in apple, but this view is difficult to accept, since it has been shown that apple made alkaline by the addition of sodium hydroxide is equally effective.

In a satisfactory case the stools soon become formed and obviously contain a good deal of cellulose residue, but it is difficult to see how the residue in itself can have a mechanical action in checking the diarrhoea ; it would rather be expected that the reverse would happen.

\section{Summary}

The effect of a diet of raw apple pulp and weak tea has been studied in thirty-six infants suffering from diarrhoea. Although the treatment is in no sense specific and does not replace other methods, it may be employed as a valuable adjunct. The diet is seen to best advantage in infants with persistent diarrhoea associated with the passage of frequent loose, offensive motions. The most noticeable effects are the lessening of toxæmia, the improvement in the stools and the rapid and sustained rise in weight. 
Thanks are due to the chief medical officer of the London County Council for allowing this investigation to be undertaken and for permission to make this report ; to Dr. A. Randall, Medical Superintendent of St. Giles' Hospital, for facilitating the analysis of the hospital records ; to Dr. Evelyn Mitchell, for supervision of the infants ; and especially to Sister McQuire for her keen interest and close co-operation both in the preparation and administration of the diet.

\section{REFERENCES}

Barondes, R. de R. (1937). Brit. J. Child. Dis., 34, 48.

Council on Food Reports (1937). J. Amer. med. Ass., 109, 1636.

Heisler, A. (1929). Ärztl. Rdsch., 39, 305.

Moro, E. (1929). Klin. Wschr., 8, 2414.

Schachter, M. (1934). Med. infant., 41, 37.

Schlesinger, B. (1936). Arch. Dis. Childh., 11, 169. 